\title{
Lambert-Eaton myasthenic syndrome: the 60th anniversary of Eaton and Lambert's pioneering article
}

\author{
Síndrome miastênica de Lambert-Eaton: $060^{\circ}$ aniversário do artigo pioneiro \\ de Eaton e Lambert \\ Paulo José Lorenzoni', Cláudia Suemi Kamoi Kay, Lineu Cesar Werneck', Rosana Herminia Scola
}

\begin{abstract}
This historical review describes the contribution of Drs. Lee M. Eaton and Edward H. Lambert to the diagnosis of myasthenic syndrome on the $60^{\text {th }}$ anniversary of their pioneering article (JAMA 1957) on the disease. There are important landmarks in their article on a disorder of the neuromuscular junction associated with thoracic neoplasm and the electrophysiological criteria for Lambert-Eaton myasthenic syndrome (LEMS). After 60 years, the main electrophysiological criteria described in Eaton and Lambert's pioneering article are still currently useful in the diagnosis of LEMS.
\end{abstract}

Keywords: Lambert-Eaton myasthenic syndrome; electromyography; diagnosis

\section{RESUMO}

Essa revisão histórica enfatiza a contribuição do Dr Lee M Eaton e do Dr Edward H. Lambert para o diagnóstico da síndrome miastênica no $60^{\circ}$ aniversário do seu artigo pioneiro (JAMA 1957) para essa doença. Existem importantes marcos no artigo de Eaton e Lambert, como uma desordem da junção neuromuscular associada à neoplasia torácica e critério diagnóstico para síndrome miastênica de Lambert-Eaton (LEMS). Após 60 anos, os principais critérios diagnósticos descritos para LEMS no artigo pioneiro de Eaton e Lambert continuam úteis no diagnóstico da LEMS.

Palavras-chave: Síndrome miastênica de Lambert-Eaton; eletromiografia; diagnóstico

In the last century, physiological techniques probing the nature of a neuromuscular transmission defect have been well established ${ }^{1}$. One of the most important is the electrophysiological test for the Lambert-Eaton myasthenic syndrome (LEMS). The main historical contribution for recognizing the physiological findings of this disease began when it was reported that patients with bronchial neoplasm and muscle weakness improved after removal of the tumor or after the use of anti-cholinesterase drugs, which suggested the concomitance of a neuromuscular transmission defect ${ }^{2,3}$. In 1956, a series of patients with unusual disorders of neuromuscular transmission associated with a malignant tumor was presented by Lambert, Eaton and Rooke at an international meeting of the American Physiological Society, and a brief note published as an abstract ${ }^{4}$. In this series, many of the clinical and electrophysiological features were carefully distinguished from those seen in myasthenia gravis, which served as a basis for a publication one year later by Eaton and Lambert ${ }^{4,5}$. This was one of the most important pioneering articles in LEMS 5 .

In 1957, this groundbreaking article was published by Eaton and Lambert in The Journal of the American Medical Association (JAMA), summarizing the core features of myasthenic syndrome and later leading to the eponym for the disease $^{3,5,6}$. Initially, the eponym was 'Eaton-Lambert syndrome' and 'Eaton-Lambert myasthenic syndrome', in reference to their pioneering work and publication in $\mathrm{JAMA}^{6,7,8}$. Recently, the eponym 'Lambert-Eaton myasthenic syndrome' (LEMS) was adopted in international publications in PubMed and other databases (July 2017), probably in honor to Lambert's contributions to the establishment of the physiological basis of the defect in the neuromuscular transmission in this disease ${ }^{7}$.

${ }^{1}$ Universidade Federal do Paraná, Hospital de Clínicas, Departamento de Clínica Médica, Serviço de Neurologia, Serviço de Doenças Neuromusculares, Curitiba PR, Brasil.

Correspondence: Paulo José Lorenzoni; Serviço de Doenças Neuromusculares, Hospital de Clínicas da UFPR; Rua General Carneiro, 181 / $3^{\circ}$ andar; 80060-900 Curitiba PR, Brasil; E-mail: lorenzoni@ufpr.br

Conflict of interest: There is no conflict of interest to declare.

Received 08 August 2017; Received in final form 07 November 2017; Accepted 21 November 2017. 
In recent years, our knowledge of the clinical and pathological features of LEMS has expanded; however, the core electrophysiological features of LEMS are identical to those in the Eaton and Lambert article. In November, 2017, this pioneering article was cited in 402 articles in the Google Scholar database, 304 articles in the Web of Science database and 198 articles in the Scopus database. In addition, in July 2017, the term LEMS could be identified in more than 1,000 articles in the PubMed database.

Both neurologists are most renowned for describing the LEMS, but they also have contributed to a wide range of electrophysiological tests and neuromuscular diseases ${ }^{1,7}$. When their article was published, Dr. Lee M. Eaton was affiliated to the Section of Neurology (Chair of the Neurology Department at the Mayo Clinic) and Dr. Edward H. Lambert to the Section of Physiology of the Mayo Clinic and Mayo Foundation (the Mayo Foundation was part of the graduate school of the University of Minnesota $)^{5}$.

This review describes historical aspects of the important contribution made by Drs. Lee M. Eaton and Edward H. Lambert to this disease in 1957 with their pioneering article in JAMA.

\section{EATON AND LAMBERT'S PIONEERING ARTICLE}

In the introduction of the article, the authors commented that several inquiries had been made about the clinical value of electromyography and nerve conduction studies, which reflected a 'broad interest among physicians". Although these procedures were previously well studied by other authors, electrophysiological tests were not widely adopted by neurologists in the middle of last century ${ }^{1}$.

To describe the test to the medical community, especially to neurologists, the article provided a detailed description of the 'electrophysiology of muscle contraction', the procedures of 'electromyographic testing', the 'value of clinical electromyography' and the importance of the additional 'electric stimulation of nerves' in the investigation of neuromuscular disorders 5 .

The argument that these procedures 'also may be used as instruments of research' was explored in the article, and the authors selected examples of diseases to show the usefulness of the procedures in clinical research ${ }^{5}$. The most important was the description of six patients 'who have a disorder resembling myasthenia gravis, which may represent a specific clinical electromyographic syndrome ${ }^{5}$.

The authors described three patients presenting with weakness (mainly in the lower limbs) associated with fatigability and absence of the muscle stretch reflexes ${ }^{5}$. The results of the neostigmine test were negative or equivocal ${ }^{5}$. All the patients had a thoracic tumor, and small cell lung carcinoma was diagnosed in two of them ${ }^{5}$. However, the electromyography studies revealed an 'unusual fatigability' of muscles in all the patients ${ }^{5}$.

Additional electrophysiological and clinical studies were done, which, although similar to those in myasthenia gravis in all patients, revealed significant differences as well ${ }^{5}$ :
Application of a single electric stimulus to the ulnar nerve resulted in a much smaller action potential of the hypothenar muscles than would have been expected on the basis of the relatively good strength of the muscles as determined clinically. This had been observed in all the patients of this group and was in contrast to the occurrence of a relatively normal response to a single stimulus in patients with myasthenia gravis of comparable severity. A series of stimuli resulted in a further transient decrease in amplitude of the potential, followed by a remarkable increase in the size of subsequent potentials, with comparable increase in the strength of the resulting twitches'.

Eaton and Lambert also confessed that their academic curiosity 'was aroused sufficiently' to search for similar cases in their records ${ }^{5}$. Three other patients were found with the same features ${ }^{5}$. Two patients had a thoracic tumor and one patient had cerebellar ataxia without an association with a tumor ${ }^{5}$.

The authors commented that neurological diseases, especially neuromuscular disorders, had recently been reported to be associated with malignant tumors ${ }^{5}$. They reflected particularly on published cases that could have similar characteristics to the new syndrome ${ }^{2,5}$ : 'Some of the reported cases, particularly those classified as myopathy, appear to be clinically similar, if not identical, to those that have interested us. In the case reported by Anderson and co-workers, electromyographic and pharmacological studies gave results similar to those seen in myasthenia gravis. However, in general, the English authors have not elaborated on the electromyographic features of the syndrome that, in our experience, seem to be of considerable diagnostic importance'.

This pioneering article is also important because it served to present the considerable clinical potential of the electrophysiological techniques in LEMS to a scientific and medical readership 9 . The authors elegantly highlighted the value of repetitive nerve stimulation in the LEMS diagnosis': 'Should this syndrome prove to be of some clinical importance, electromyography and stimulation of nerves must be given the greatest credit. Without these techniques, the syndrome would have been confused with myasthenia gravis and its significance would have continued to elude us'.

Eaton and Lambert's article summarized the main clinical features in detail, and established the electrophysiological criteria of LEMS. The electrophysiological criteria were characterized in the comments that highlight the "marked facilitation' (incremental response of the compound muscular action potential) after high-frequency repetitive nerve stimulation and voluntary contraction, the identification of which was an important landmark for LEMS and electrophysiological tests 5 . The incremental response was not quantified in the article. Further recommendations added that increments greater than $100 \%$ should be observed as more accurate (gold standard) to confirm the diagnosis of LEMS ${ }^{10}$. Even after 60 years, the main electrophysiological criteria for LEMS described in Eaton and Lambert's pioneering article are still useful in the LEMS diagnosis. 
1. Kazamel M, Warren PP. History of electromyography and nerve conduction studies: a tribute to the founding fathers. J Clin Neurosci. 2017 Sep;43:54-60. https://doi.org/10.1016/j.jocn.2017.05.018

2. Anderson HJ, Churchill-Davidson HC, Richardson AT. Bronchial neoplasm with myasthenia; prolonged apnoea after administration of succinylcholine. Lancet. 1953 Dec;265(6799):1291-3. https://doi.org/10.1016/S0140-6736(53)91358-0

3. Goodrick S. Lambert-Eaton myasthenia. Lancet Neurol. 2015 Apr;14(4):357. https://doi.org/10.1016/S1474-4422(15)70057-8

4. Lambert EH, Eaton LM, Rooke ED. Defect of neuromuscular conduction associated with malignant neoplasms. Am J Physiol. 1956;17:612-3.

5. Eaton LM, Lambert EH. Electromyography and electric stimulation of nerves in diseases of motor unit; observations on myasthenic syndrome associated with malignant tumors. J Am Med Assoc. 1957 Mar;163(13):1117-24. https://doi.org/10.1001/jama.1957.02970480021005
6. Kennedy WR, Jimenez-Pabon E. The myasthenic syndrome associated with small cell carcinoma of the lung (Eaton-Lambert syndrome). Neurology. 1968 Aug;18(8):757-66. https://doi.org/10.1212/WNL.18.8.757

7. Simpson JA. Electrophysiology of neuromuscular junction disease: an appreciation of the contributions of Edward $\mathrm{H}$. Lambert. Muscle Nerve. 1982;5(S9):S6-11.

8. Babakova LL, Kolomenskaia EA, Ostrovskaia NV, Pozdniakov OM. [Neuro-muscular synapse ultrastructure in the Lambert-Eaton myasthenic syndrome]. Biull Eksp Biol Med. 1976 Jan;81 (1):79-80. Russian. https://doi.org/10.1007/BF00800181

9. Newsom-Davis J, Murray N, Wray D, Lang B, Prior C, Gwilt M et al. Lambert-Eaton myasthenic syndrome: electrophysiological evidence for a humoral factor. Muscle Nerve. 1982;5(9S):S17-20.

10. AAEM Quality Assurance Committee. American Association of Electrodiagnostic Medicine. Practice parameter for repetitive nerve stimulation and single fiber EMG evaluation of adults with suspected myasthenia gravis or Lambert-Eaton myasthenic syndrome: summary statement. Muscle Nerve. 2001 Sep;24(9):1236-8. https://doi.org/10.1002/mus.1139 